\title{
Construction of Multi-Level All-Dimensional Platform for Basic Experimental Teaching
}

\author{
Midan $\operatorname{Li}^{1, a}$
}

\author{
${ }^{1}$ Beijing Institute of Graphic Communication, Beijing, PR China \\ alimidan@bigc.edu.cn
}

\begin{abstract}
A basic experimental teaching platform was constructed drawing on the teaching reform in many colleges and universities, while considering the characteristics of the school. Aimed at the problems produced during the development of the platform, such as the imperfect teaching system, separate discipline laboratories, single experimental teaching function and backward management mechanism, the new multi-level experimental teaching system is organized, which consisting of demonstration experiments, basic experiments, design experiments, comprehensive experiments and research experiments, the teaching function of platform is expanded in many ways, the teaching management mechanism is established based on information technology, and the industry characteristics and cross-disciplinary integration are highlighted. The practical effect of reform is satisfactory.
\end{abstract}

Keywords: multi-level, all-dimensional, basic experiments, teaching platform

\section{多层次立体化基础实验教学平台建设}

李密丹 $1, \mathrm{a}$

${ }^{1}$ 北京印刷学院, 北京, 中国

alimidan@bigc.edu.cn

\section{摘要}

借鉴兄弟院校教学改革经验, 结合学校实际情况, 组建了基础实验教学平台。针对平台发展过程中存 在的教学体系不完善, 各学科实验室各自为政, 实验室功能单一, 实验室教学环境及教学管理机制较 为落后, 实验室开放度及有效利用率低等问题，构建了由演示实验、基础实验、设计性实验、综合性 实验和研究性实验构成的多层次实验教学新体系, 从多角度拓展了平台教学功能, 建立信息化教学管 理机制，同时突出行业特色和学科交叉融合，全面提升了基础实验教学水平，取得了良好的效果。

关键词：多层次，立体化，基础实验，教学平台

\section{1. 引言}

基础实验教学 (包括数、理、化三门学科) 是工科学生进 入大学后接受实践教育的开端, 在人才培养中具有尤其重 要的地位, 它能提供系统、全面、综合性很强的实验技能 训练, 是培养学生科学实验能力、创新思维能力、提高科 学素养的重要基础。它在培养学生严谨的治学态度、活跃 的创新思维、理论联系实际和适应科技发展的综合应用能 力等方面具有其它实践类课程不可替代的作用。基础实验 教学质量能否取得实质性的提高, 取决于能否够构建起科 学合理的基础实验教学平台。另外, 随着新高考综合改革 的全面推进, 工科院校生源结构将发生巨大变化, 为适应 生源变化, 推行因材施教, 分层分流培养, 分类成才成为 基础教学重点工作之一。因此构建多层次立体化基础实验 教学平台已成为基础实践教育的首要工作。

许多工科院校对基础实验教学进行了大量的改革探索和 实践, 取得一定教学改革成果 [1-4]。本文在借鉴兄弟院校 教学改革经验基础上, 结合学校实际情况, 构建了具有多 层次教学体系、立体化教学功能的基础实验教学平台, 同
时突出行业特色和学科交叉融合, 全面提升基础实验教学 水平。

\section{2. 基础实验教学现状与问题}

基础实验教学经过多年发展, 实验室规模、整体实力水平 得到一定程度提升, 实验室管理体制不断完善, 实验教学 改革取得一定实效，形成了布局基本合理、能够基本满足 现有基础实验教学需要和初步创新教育需要的实验教学 体系。但新时期带来了新问题，新高考综合改革的全面推 进, 学校生源结构将发生巨大变化, 迫切需要按照因材施 教原则构建多层次实验教学体系; 除此之外，与同类院校 以及学校发展目标要求相比, 基础实验教学还存在很多问 题和差距。

\section{1. 教学理念落后}

主要存在以下几个方面的问题: 1)基础教学环节重理论轻 
教学需求, 直接影响教学水平的提高, 阻碍教学改革的进 行。为提高管理效率, 目前各院校均在积极进行信息资源 平台的建设, 通过平台, 可以实现信息资源网络化管理, 实现仪器设备共享, 提高设备利用率, 提高实验教学的质 量, 促进教学改革。

\section{3. 多层次立体化基础实验教学平台建设}

建设的总体目标是逐步建成以本科教学为根本, 以创新教 育、留学生教育为引领, 兼具社会化服务功能, 具有行业 特色, 具备先进教学理念和创新管理机制, 涵盖数理化三 门学科的多层次立体化基础实验教学平台。

\section{2. 教学体系不够完善}

在课内实验常规教学中, 经过多年不断实践积累, 已经形 成了演示实验、基础实验、设计性实验三个层次的实验教 学体系。但是按照教育部高等学校教学指导委员会制订的 实验课程基本要求（2010 年）, 缺少综合性、研究性实 验层次。此外生源结构的变化也需要在基础实验层次进行 更进一步的层次细化。

\section{3. 教学手段较为原始}

传统实验教学要求学生在固定时间、固定地点做固定的实 验, 实验进程的主导者是教师, 留给学生独立探索和实践 的机会很少。传统实验教学的教学方式都采用板书或 PPT 再加讲授的方式, 信息化手段几乎没有。除了课堂以外, 教师与学生互动少, 教师对学生学习状态数据一无所知, 学生也难以获得灵活的学习指导, 因此无法调动学生学习 积极性，甚至会扼制学生的个性发展。

《国家中长期教育改革和发展规划纲要》指出, 信息技术 对教育发展具有革命性影响, 必须予以高度重视。将信息 技术融入基础实验教学, 一方面实现课程教学手段现代 化, 另一方面信息技术手段的应用也拓宽了学生的视野, 多方位激励学生, 对学生综合素质的提高和创新能力的培 养起着积极的推动作用。

\section{4. 各学科实验室各自为政, 资源得不到有效 利用}

与物理、化学、数学学科相配套的三个实验室相互独立, 各自为政。各种教学资源包括硬件设施、师资、空间、管 理等得不到有效利用。

\section{5. 教学功能单一}

目前基础实验教学主要功能服务于本科常规教学, 有初步 的创新教育, 规模小, 不系统。

\section{6. 管理机制较为落后}

以手工为主的传统实验室管理方式, 已难于适应当前实验

\section{1. 明确指导思想, 凝练教学理念}

坚持全过程与全方位育人以及提高学生综合素质为总出 发点, 坚持战略前瞻性、规划科学性、建设实用性的基本 原则。统筹规划、明确目标、突出重点、分步实施。

以 “加强基础、面向专业、分层培养、鼓励创新” 为教学 理念, 进行有利于学生个性化发展, 有利于创新, 有利于 科学素质和综合素质协调发展的实验教学改革。

\section{2. 成立基础实验教学中心}

打破学科界限, 将现有物理实验教学中心、化学实验室、 数学实验室合并, 重新布局, 成立基础实验教学中心。中 心在级别上与教研室平行, 设置中心主任, 中心下设物理 实验室、化学实验室和数学实验室。合并后各种教学资源 包括硬件设施、师资、空间、管理等可以达到高度共享, 形成合力。

\subsection{1. 构建多层次课内实验教学体系}

实验教学的根本目的是培养学生的实际应用能力, 能力的 培养是一个循序渐进的过程, 从感性认识到基本能力的形 成再到创新能力的培养, 逐层深入, 实验教学体系的设置 应该依据认知规律, 体现多层次性 [5,6]。因此构建了由演 示实验、基础实验、设计性实验、综合性实验、研究性实 验构成的多层次实验教学体系; 此外, 为应对高考综合改 革背景下我校生源结构的变化, 还需进一步细化基础实验 层次。随着我校留学生规模的扩大, 探索面向留学生的基 础实验教学体系也势在必行。

\subsection{2. 实验室建设}

在课程体系改革的同时, 进行与教学体系相配套的实验室 建设。改革前已有演示实验室和基础实验室, 设计性实验 没有独立实验室, 行课穿插在基础实验室进行, 这也是设 计性实验十多年来没有进一步发展的重要原因。以新实验 楼建成为契机, 对实验室进行了调整、重组和新建, 按功 能划分为演示实验室、基础实验室、综合性实验室和设计 性实验室, 满足多层次实验课程教学体系改革的需要。 


\subsection{3. 提供社会化服务}

\subsection{3. 建立开放式教学模式}

改革原有的实验课教学模式, 逐步实行实验时间开放、实 验空间开放和实验内容开放, 满足学生自主式实验方式、 合作式实验方式和研究式实验方式等多种实验教学形式 的需求, 调动学生自主学习的积极性, 激励个性, 培养 创新意识。开放形式分为实验课外延部分、课外科技小组 预约、个人独立探索式预约。探索并完善不同的实验室开 放管理机制, 提高学生实验学习积极性, 进而提高实验教 学质量。

\subsection{4. 突出行业特色，发挥学科交叉优势}

立足于行业, 在教学内容设置上突出行业特色。在综合性、 设计性、研究性实验层次教学中, 针对不同专业学生开设 既有基础理论思想又与专业相关的实验项目。成立基础实 验教学中心, 不是数理化三门学科实验室简单的合并, 要 做到真正有机的融合。合并后, 各类学科竞赛、创新创业 计划、学生科研计划等, 打破学科界限, 各学科教师共同 参与, 提高了学生科研项目水平和竞争力。

\section{3. 构建课内外立体化教学平台}

中心功能除完成常规本科课内实验教学外, 还构建并完善 了课内外创新教育平台, 服务留学生教育, 提供社会化服 务。

\subsection{1. 构建课内外创新教育平台}

创新教育平台分成两个层次建设, 即课内大众创新教育平 台和课外精英创新教育平台。

课内大众创新教育平台, 面向全院工科专业以选修课及开 放实验形式提供。基础实验教学作为学生实践教育的起始 阶段, 应该注重对所有学生的创新意识和创新能力的培 养, 不能急于去追求创新成果。大众创新教育平台面向全 院工科专业开放, 学生受益面广。以物理实验室作为试点, 面向全校工科学生重开《创新性物理实验》选修课; 组建 全开放创新物理实验室, 初期配备 20 余项创新实验项目, 同时引进先进的智能化实验开放管理系统, 彻底打破传统 实验教学的束缚, 尽最大努力达到真正意义上的开放, 自 选项目，自定时间，自拟方案，独立完成。

课外精英创新教育平台, 面向优秀的学生, 以各类学科竞 赛、创新创业训练计划、学生科研计划等形式开放。

\subsection{2. 服务留学生教育}

随着留学生规模是逐年扩大, 工科专业, 如自动化、机械 工程、计算机等的本科生和研究生对基础教学需求也随之 增大, 这些学生的数理化等基础课程也开展了实验教学, 服务留学生教育是基础实验教学平台的功能之一。
北京市教委高等教育处 2017 年工作要点中指出, 推进北 京优质教育资源开放共享, 引导高校资源面向社会适度开 放。中心也在努力寻求向社会开放的途径, 扩大社会影响 力。主要从两个方面着手: 一是探索建设中小学生实验实 践课程基地; 二是探索校际间共享实验室。

\section{4. 管理制度建设}

\subsection{1. 健全运行管理机制}

基础实践教学平台的构建是一个系统工程，一个完善的 运行管理机制是取得改革成效的根本保证 $[7,8]$ 。提升基础 实验教学中心级别, 与教研室平行, 设置中心主任。明确 中心主任岗位职责及实验技术人员职能, 解决业务与岗位 不匹配的矛盾, 将实验技术人员从教学中逐渐剥离出来, 主要精力放在实验室日常管理、实验室建设、学科竞赛的 组织与管理等方面。

\subsection{2. 实现实验教学智能化管理}

对中心实验环境进行改造, 创造了良好的实验室科学、文 化氛围, 设置一批与各学科实验有关的文化梪窗、展板等。 下一步要安装电子门禁控制系统、安防报警及监控系统、 智能一卡通系统, 通过这些控制手段实现实验室智能化自 助式管理。引进实验教学管理及选排课系统, 利用网络化 信息手段实现实验室管理、实验教学管理和学生预约管理 的高效智能化。

\section{4. 结论}

多层次立体化基础实验教学平台的建立,打破了过去长期 形成的实验教学体系不完善, 基础实验教学功能单一的困 局，不仅构建了包括演示实验、基础实验、设计性实验、 综合性实验和研究性实验构成的多层次实验教学新体系, 而且拓展了平台教学功能, 形成了除常规实验教学外, 还 具有创新功能, 同时服务留学生教育, 提供社会化服务。 在建设过程中, 突出行业特色, 充分发挥学科交叉优势。 通过几年的努力建设, 学生在基础实验学习中获得感大幅 提升, 学习积极性、主动性、协作性均有过提高, 各学科 交叉融合取得一定成效, 各级各类竞赛获奖质量明显提 高, 同时学生科研项目数量和质量也有所提升。

\section{致谢}

本文为北京印刷学院重点教改项目《多层次立体化创新型 基础实践教学平台的构建》(22150118002)的阶段性成果 之一。 


\section{参考文献}

[1] 黄凯, 凌辉, 潘禁. 北京大学国家级地球科学实验教学 示范中心的建设与实践 $[\mathrm{J}]$. 实验技术与管理, 2014 , 31(12):1-5.

[2] 沈山, 王友建, 管华.参与式研究型实践教学实验中心 的建设与实践 [J]. 实验室研究与探索, 2014 , 33(11):149-152.

[3] 王国霞.立体化实验教学体系的建设与实践 $[\mathrm{J}]$. 实验 室科学, 2016, 19(4):134-137.

[4] 王莉, 王文顺, 倪国栋. 土建类专业 “虚实结合” 实 践教学体系及平台建设探讨 $[\mathrm{J}]$. 教育教学论坛, 2019, 8:74-76.

[5] 王国强, 傅承新. 研究型大学创新实验教学体系的构 建 $[\mathrm{J}]$. 高等工程教育研究, 2006, 1:125-128.

[6] 王立英, 秦珠, 廖怡, 戴海涛, 米文博. 新工科下多学 科交叉创新性物理实验课程改革 $[\mathrm{J}]$. 大学物理, 2019, 38(9):43-49.

[7] 秦平力, 余雪里, 张昱. “互联网+” 背景下大学物理 实验教学创新与探索 $[J]$. 物理通报, 2019, 31:100-109.

[8] 梁平, 任建民, 张云霞, 史艳华. “四平台、三层次、 开放式、一体化” 的石油化工装备实验教学中心建设及实 践 $[\mathrm{J}]$.化工高等教育, 2018, 6:27-31. 